\title{
How can regional assets capitalization add value to a modern economy? A theoretical approach
}

\author{
Adriana PETRE \\ The Bucharest University of Economic Studies, Bucharest, Romania \\ adriana.petre4@gmail.com
}

\begin{abstract}
In a world where social needs surpass the effective resources meant to meet them, in a world where social change might be triggered by false expectations, scientists have joined forces with the private and public actors in order to exploit the full potentiality encountered at the regional levels. If we make a comparison between the social levels and the regional levels we might find astonishing similarities between a reference network and a cluster because they are both networks. The similarity is relevant from the behavioural point of view because any change in the society, be it at the social, economic, cultural, political, natural level is ignited by the human factor. Territorial capital, the innovative notion that reunites the productive assets found at the level of a territory, has been placed in the light of the current research given its potential in indicating economic growth and competitive advantage at the level of a territory. Being essentially a conceptual paper, this article extends the literature by offering a theoretical perspective on the terminology needed to understand territorial capital, to discover the possibilities of creating shared value process at different regional levels and, eventually, to analyse the capitalization concept, considering it an efficiency and social change generating tool in the regional economy. This paper is intended to bring a different, original, perspective at the theoretical level through the way in which the three core concepts are analysed in a common frame. Using the qualitative research methodology and the investigation of literature as a core research method, the conclusion reached was that the above mentioned concepts are interlinked conceptually. As far as the applicability of their relationship is concerned, this paper sets just the beginning of an in-depth research of these relevant fields of study.
\end{abstract}

Keywords: territorial capital, creating shared value (CSV), capitalization, regional economy, social change.

\section{Introduction}

What are those features or values that territorial capital only can provide in order to create a competitive advantage at the business level? In the sense of proceeding into discovering this dilemma, I firstly try to define the term of territorial capital and then to analyse it in the same context with the concepts of creating shared value, cluster and capitalization of regional assets.

We are facing times when capitalism is reengineered and „a wave of innovation and growth" is unleashed (Porter and Kramer, 2011). Nowadays the big economic players have understood that corporate social responsibility is not enough anymore. This era is dedicated to corporate shared value, which „creates economic and societal benefits relative to cost, involves new and heightened forms of collaboration, realigns the entire company budget" and, what is more striking, it does not act just in response to competition, but fosters beneficial competition and profit maximization. These and many other advantages have been made possible in regions where the government manifested a flexible attitude and adjusted regulation for the common benefit. However, as the authors state, „not all societal problems can be solved through shared value solutions", but their final point is that 
the small steps have brought a more respectful image of the companies in the communities they activate.

The paper has the objective to analyse the theoretical ideas that revolve around the concepts of territorial capital and its connection with creating shared value and capitalization process developed at a regional level. Social and economic assets make the common ground between the CSV and territorial capital and those will be the ones taken into discussion in order to discover a correlation between the two concepts. Is the regional economy the common field which can connect them or the relativity given by the novelty of the concepts is still dominant?

\section{Literature review}

\section{Capitalization of territorial assets}

The concept of territorial capital is relatively new in the social sciences arena and it came as a revelation and an ultimate measuring tool for the economic growth of a territory (Tóth, 2011). This complex indicator of the economic, social, geographic and cultural factors found at the level of a territory, be it city, cluster, country or region, finds its utility especially in the cases of measuring intangible assets. So far they were impossible to measure through quantitative methodologies, generally accepted and universally recognized as reliable, and the qualitative or mixed ones were not so common. Therefore the image on the potential found at the level of a territory was until present times distorted, but now it has become quantifiable from the social and economic point of view and, as such, "operationalizable" (Tóth, 2011, p.3). Also, as Tóth (2011, p.2) synthesizes, "territorial capital is a complex measuring tool which can be used to examine and measure the tangible and intangible capital factors of the space structure."

The first attempt to address the assets from a territory was made in 1993, when Kretzman and McKnight included in their paper the term of "community development assets", introduced by the Asset Based Community Development. Although there can be found similar grounds with the term of territorial capital, they differ in terms of focus, as the first tries to identify the negative sides of the assets in order to create policies to address social and economic conflicts, while the second is oriented towards finding the assets which generate actual local success (Camagni and Capello, 2013, p. 1399). Therefore, this makes the difference between a policy which speculates the full half of the glass or the empty half.

The current meaning of territorial capital has its roots in a regional policy OECD proposal (2001) and has been used by DG Regio of the EU Commission since 2005:

„Each Region has a specific territorial capital that is distinct from that of the other areas and generates a higher return from specific kinds of investments than the others, since these are better suited to the area and use its assets and potential more effectively. Territorial development policies (policies with a territorial approach to development) should first and foremost help areas to develop territorial capital" (European Commission, 2005, p.1).

In other views, territorial capital can be explained as "the system of territorial assets of economic, cultural, social and environmental nature that ensures the development potential of places. The potential of this concept resides in the recognition of possible interactions between factors of different nature."(Perucca, 2014). Territorial capital has a 
different meaning for each state and region because capital is multidisciplinary, being „based on a foundation of different sciences [...] (geography, economy, etc.” (Silka, 2013). The concept „is holistic, it has perspective, and it is able to explain territorial processes in its dynamics" (Tóth, 2011, p.141).

What it is more important to be taken into consideration is the fact that territorial capital actually reunites tangible and intangible assets which have the role of a factor of production. „Nevertheless, according to empirical analyses, like any factor of production, territorial capital follows the law of decreasing marginal productivity." (Camagni and Capello, 2012) This law has to be extremely well understood especially by policy makers, but also by the rest of stakeholders whose target is territorial assets capitalization. In a world in which competitiveness becomes the decisive vector, the referential societal actors, be they private or public, take the territorial capital as a landmark for a long term sustainable competitive advantage.

\section{Levels of territorial capital under CSV revolution process}

Territorial capital tries to explain the considerable support of the qualitative determinants to the added value in the modern economy, adding the use of intangible assets like entrepreneurship, creativity, know-how or behavioural models and values to the tangible and mixed assets (Camagni, 2009).

On one side, in the literature can be found three theoretical models used to describe the structure of territorial capital, designed by OECD (2001), Camagni (2008) and Tóth (2011). As far as Tóth model is concerned, it describes territorial capital as a sum of tangible and intangible assets. The tangible ones measured quantitatively by using the GDP are the produced capital, the financial and investment capital. The intangible assets, however, are identified as intellectual capital, human, psychic, creativity, knowledge, organizational, relation, cultural and social capital.

On the other side, from a more applied perspective, Cojanu and Popescu (2016), for example, develop a map of territorial capital endowments at the European regions (clusters) by analysing the social and economic assets, the creativity, the natural assets in correlation with the regional level of development measured also by GDP at current market prices and net disposable income.

The idea that territorial capital can revolutionize the regional policy and the regional economic development is drawing the new patterns of the literature. However, only the acknowledgement without the proper human resource specialization in the field and without a general consensus on the matter from the decision-makers and the private stakeholders would not generate what now is called the creating shared value (CSV) process.

Social and economic assets are elements of territorial capital, but simultaneously they are part of creating shared value (CSV) process, therefore there can be analysed a direct relationship between territorial capital and CSV. But what is CSV?

On the one hand, Porter and Kramer (2011, p.4) first introduce the term in the January-February issue of Harvard Business Review, where they present it like "the big idea". They see the process of creating shared value as a manner of "creating economic value in a way that also creates value for society by addressing its needs and challenges". The aims of this process, indicated by the authors (2011) are "to re-legitimize business", to 
redesign "the purpose of the corporation”, to „reshape capitalism” and to „supersede corporate social responsibility in guiding the investments of corporations in their communities".

In the cited text, there are also provided three ways in which the companies might generate shared value, and these are, by „reconceiving products and markets, redefining productivity in the value chain and enabling local cluster development (Porter and Kramer, 2011, p. 5)." Therefore, the challenge of this millennium for the companies seems to be finding the optimal formula which enables them to link their success with social progress.

Moreover, the study follows a comparison between creating shared value and corporate social responsibility, underlying the advantages of the first over the second in terms of profit maximization and by being more oriented towards creating growth and not on building reputation.

On the other hand, in response to Porter and Kramer's publication, Crane et al. (2014) have written a controversially critical article, analysing the pluses, but more fervently, the minuses of the creating shared value concept. The strengths underlined in their paper relate to the great receptivity of practitioners and scholars towards the new concept, then they appreciate the contribution of the paper on bringing about social targets as current priorities, in underlying the role of the governments in fostering a responsible behaviour and adding connection between concepts related to capitalism.

The limitations observed by the authors (Crane et. al, 2014, p.131) are related to the fact that CSV is not original, as a large number of papers on social innovation, CSR and management of stakeholders have already pointed some of the main characteristics of the pretended new term. The expectations of the authors to replace CSR by its newer and better version of CSV (Porter and Kramer, 2011) are under critique of Crane et al. Also, the term does not take into consideration the opposition between social and economic scopes and it is founded on a limited view of corporations' role and challenges in society.

As far as the three dimensions of CSV given by Porter and Kramer (2011), Crane et al. (2014), had a word of comment as well. The main point is related to the cluster development aim because the article "fails to deliver orientation for a responsible corporate-wide strategy" and focuses more on isolated successful cases of "win-win projects", which are determined more by the potential of the industry and less by the social need.

Having the definition of CSV given by Porter and Kramer (2011) as a reference, I observed the emphasis on the role of CSV in addressing the needs of the society. Therefore, I considered that a part of the changes happening in society either at social or economic levels are ignited by the human factor. I started to ask myself, is the process of creating shared value the example of an independent set of actions or a rather interdependent one?

According to behavioural sciences, independent actions refer to that particular situation when we do not pay attention to what other people do or think we should do, while the interdependent ones are exactly the opposite. Involving a great variety of stakeholders, CSV is definitely based on interdependent actions. We can turn an action from independent to interdependent when we share it with individuals who matter to us when we make a decision. These individuals form a reference network (Bicchieri, 2016). However, not everybody in the reference network covers the same status, one's opinion is more important for the decision maker that the other's. The structure of the reference 
networks is also a criteria well pointed by Bicchieri (2016), as they can be centralised or distributed, the latter having a better dispersed information process than the former one.

The concept of reference network is in a sense analogous to the one of cluster because they are both networks, but in different contexts and at different scales. A reference network is defined as „a set of individuals who matter to us when making decisions and which varies from situation to situation, changing its structure from centralised to distributed”(Bicchieri, 2016), while a cluster is „a geographic concentration of firms, suppliers, related industries, and specialized institutions that occurs in a particular field in a nation, state, or city" (Porter, 2008) also adaptable to the factors found at the level of the region.

As Porter (2000) observes, the firms in a cluster have the ability to „perceive new buyer needs" more clearly and rapidly. The relationships within a cluster are extremely complex, like the ones from a reference network. The influence that a cluster holds on competition (increasing current productivity of constituent firms, increasing innovation and productivity growth of the participants and stimulating new business formation) is mostly dependent on the quality of the personal relationships, on face-to-face communication and on the networks of individuals and institutions that interact. A cluster is an extremely alive structure, whose development is influenced by „formal and informal organizing mechanisms and cultural norms".

The reference network becomes extremely relevant when it comes to an individual's decision-making process, just like in the cluster where all the entities that form the Porter's diamond are considered before the decision is submitted.

The clusters, as "geographic concentrations of trades and companies" (Porter, 2000, p.16), range from the scale of a region, to the one of a state or just one city or even includes the nearby or neighbouring countries. The geographic scale depends on the distance necessary for the informational, transactional, incentive and other efficiencies flows to be effective (Porter, 2000, p.16). In the case of a reference network, however, geographic limitations are not encountered because one can care about a relative opinion, according to cultural or religious customs, even if that relative lives on a different continent.

In 1997, Elkington brought about the triple bottom line concept, which adds another perspective to the understanding of CSV concept. It states that companies should take into consideration three accounts called "the 3P's": people (human resources), planet (natural resources) and profit (financial resources). It represents a measure of the social, environmental and financial performance of a company during a definite period of time, mostly one year. It is a signal that the economist triggers to support a balanced approach of a company towards the resources it uses and also it diverts the board's vision from the profit-making process. The question raised is the following, how can the three dimensions be interlinked where there is an impossible trinity type of relationship while considered together? As proven from the business evidence, the theory can become functional and give favourable results only when experiencing separately the following types of focus: ecological-economical, economical-social and social-ecological.

The conclusion after analysing these controversial papers is that CSV is part of a field of research submitted to relativity. The definition and the related concepts are not standardised, so the current proposed definitions are being used according to the rename and credibility of the authors. In this particular case there are advantages because there is 
flexibility, understanding and encouragement for further contributions. But there are also expectations for better and more applied discoveries. If controversy revolves around creating shared value notion, it is inevitable that a relationship between territorial capital and creating shared value cannot be described with a degree of certainty that would ensure a validation. Further research based on quantitative analysis is expected to allow a more conclusive hypothesis analysis.

PICBE | 839

\section{Capitalization - efficiency boosting tool in the regional economy}

Lyshchikova et al. (2016), in their admirable attempt to deliver a holistic theoretical and methodological analysis on the capitalization of the resource regional potential, offer four possible explanations of the process found in the dedicated literature:

1. The process of accumulation of the productive regional capital which is carried out in various ways (the growth of the value of regional assets) - Knyaginin (2003), Malova (2007)

2. The process of involvement of resources of the region in economic turnover and their transformation into the capital - Molchan (2011), Kolesnikov (2012), Darmilova (2007), Chernyshyov (2007), Pereslegin (2005)

3 . The process of changing forms of the regional capital - Nemkovich and Savelyev (2008), Yevstigneyeva and Yevstigneyev (2010)

4. The estimated characteristic of cost of the existing regional capital (the method of estimation of cost of assets of the region) - Arabkin (2003), Dedkova (2008), Tsybulsky and Silifonkina (2010)"

However, the authors criticize the fragmented views on the understanding of this term and conclude that a holistic view is necessary, as nowadays capitalization means "the transformation of any resource into the capital" (Lyshchikova et al., 2016), be it of economic, social, cultural, environmental, political nature, tangible or intangible.

The connection between the productive factor of territorial capital and the capitalization process can be drawn through a „reproductive, geo-economic institutional and multi-level system" (Lyshchikova et al., 2016, p. 1686). This is called regional economy and it „can be represented as a complex multi-level system which consists of a plurality of interacting subsystems, components, connections, integrated into the structure" (Kolesnikov, 2012).

Paul Krugman (1991), the father of economic geography, has been studying the influence of location of factors of production to the returns of a company. As Lyshchikova et al. (2016) observe, generally, world economic resources are distributed in an uneven manner between countries and regions and even at regional level the patterns of distributions are extremely diverse. Therefore, in order to generate efficiency at the production level, techniques and resources have to be combined differently. This is how cooperation and specialization carefully planned unleash "the unification of the production, financial, intellectual and other resources in the territorial structure of the reproduction on the basis of the latest industrial infrastructures" (idem, 1688).

\section{Methodology}

The paper has a fundament on a constructivist philosophical approach. As Creswell (2013, p. 37) explains, this worldview is combined with interpretivism and is common to 
qualitative research designs. It is used in order to understand multiple views, which incentivize the researcher to broaden the field of research and the scope of the studies' questions. In the paper, I followed a qualitative research design and I considered as main method of research the investigation of the literature related to the main concepts analysed, territorial capital, creating shared value and capitalization, combined with an in-depth analysis. Given the complexity of the analysed terms, a quantitative research design would contribute to drawing a more comprehensive conceptual picture and will make the objective of a following research paper.

\section{Conclusion}

This paper intended to create a conceptual link between territorial capital, creating shared value, clusters and competitive advantage and capitalization, as being part of a relatively new terminology connected to social innovation and public and private awareness.

Creating shared value, although disputed from the conceptual and originality point of view is represented by economical-social relationship. As Porter and Kramer (2011) observed, there should be a strong cooperation between the societal actors in order to facilitate collaboration for the better course of the society and for the company overall. Eventually, shared value, defined through benefits relative to costs, should put an end to the continual "trade-off" between the social benefit and the company's benefit and facilitate the cooperation and the win-win type of relationships as a desired outcome.

What I also want to point is that it is important to have empirical expectations when we want to coordinate with others and in our case territorial capital and CSV have the relational-social and economic factors as a common element. Professor Bicchieri (2016) also states that coordination implies a two-way belief as it is based on multilateral expectations. Imitation however involves just a one-way belief and has its fundament on unilateral expectations. In my opinion the best way to promote knowledge-based assets is through coordination.

Capitalization, seen as "the process of involvement of resources of the region in economic turnover and their transformation into the capital" (Lyshchikova et al., 2016) can be understood as a systematic approach starting from local, microeconomic levels and going to the regional and national levels. As a complex process it involves complex relationships among the participant entities concentrated on finding value from the existing material resources and enabling possibilities to create immaterial resources.

As far as the current research shows, the link between territorial capital perceived as a factor of production and capitalization is proved at the regional level, as Lyshchikova et al. (2016) stated. However, by induction we can consider that the social and economic assets that form territorial capital are interlinked with creating shared value, which focuses on this level. Nevertheless, the assumed hypothesis has not yet been validated on a representative sample, this being the scope of a future research paper.

Although the research does not claim to cover in an exhaustive manner the literature, the process undergone definitely contributes to raising awareness regarding the relevance of the concepts in the same context and the further study of the correlations and causalities that may exist between the element of territorial capital and shared value at regional level in a modern economy is expected. 


\section{References}

Bicchieri, C. (2016). Diagnosing norms. In Norms in the Wild, Oxford, UK: Oxford University Press, Accessible on Coursera, 1, 6-9.

Camagni, R. (2009). Modelling futures of regional development and the concept of Territorial Capital. Colloquium on Sustainability, Disparities and Polycentricity. Retrieved from http://www.gis.cvut.cz/disparity/Camagni.pdf.

Camagni, R. and Capello, R. (2013). Regional Competitiveness and Territorial Capital: A Conceptual Approach and Empirical Evidence from the European Union, Regional Studies, 47(9), 1383-1402.

Cojanu, V. and Popescu, R. (2016). A map of European territorial capital - analytical implications. Future of Europe International Conference.

Crane, A., Palazzo, G., Spence, L.J and Maten, D.(2014). Contesting the Value of "Creating Shared Value": University of California, Berkley, 56(2).

Creswell, J. W. (2013). Research design: Qualitative, quantitative, and mixed methods approaches. Sage publications.

Dash Nelson G, Rae A. (2016). An Economic Geography of the United States: From Commutes to Megaregions. PLoS ONE 11(11): e0166083.

European Commission. (2005). Territorial State and Perspectives of the European Union, Scoping Document and Summary of Political Messages, May, European Commission, Brussels.

Fratesi, U., Perucca, G. (2014). Territorial Capital and the Effectiveness of Cohesion Policies: an Assessment for CEE Regions. Investigaciones regionals, 29, 165-191.

John Elkington (1997). Cannibals with Forks: The Triple Bottom Line of Twenty-First Century Business. Capstone, Oxford.

Krugman, P. (1991). Increasing Returns and Economic Geography: The Journal of Political Economy, 99(3), 483-499.

Lyshchikova, J.V., Orlova, A.V., Nikulina, Y.V., Anokhin, Y.I. (2016). Regional Resources Capitalization: Theoretical and Methodological Basis. International Journal of Economics and Financial Issues, 6(4), 1684-1689.

Macerinskiene, Irena, and Simona Survilaite. (2011). Company's value added and its intellectual capital coherence/Imones pridetines vertes ir jos intelektinio kapitalo sasaja.Business: Theory and Practice, 12(2), 183.

Organisation For Economic Co-Operation And Development (OECD). (2001). OECD Territorial Outlook. OECD, Paris.

Perucca, G. (2014).The Role of Territorial Capital in Local Economic Growth: Evidence from Italy. European Planning Studies, 22 (3), 537-562.

Porter, M.E. (2000). Location, Competition, and Economic Development: Local Clusters in a Global Economy. Economic Development Quarterly, 14(1), 15-34.

Porter, M.E. (2008). On Competition. Harvard Business School Publishing Corporation, USA.

Porter, M.E., Kramer,M.R. (2011). Creating Shared Value. How to reinvent capitalism - and unleash a wave of innovation and growth. Harvard Business Review, JanuaryFebruary, 63-70. 
Silka, P. (2013). Warsaw regional forum 2013.Territorial capital - concepts, indicators \& policy. Book of abstracts. Ministry of Regional Development, Republic of Poland.

Tóth, B.I. (2011). Changing Endogenous Development: The Territorial Capital. Journal of Economics and Business Research, 17(2), 137-151.

PICBE | 842 